\title{
ALÉM DOS REGISTROS INSTRUMENTAIS: A METODOLOGIA QUALITATIVA NA CONSTRUÇÃO DE PESQUISAS DA GEOGRAFIA DO CLIMA
}

Lidiana de Pinho Mendes ${ }^{1}$ José Tadeu Garcia Tommaselli²

\begin{abstract}
Resumo: O objetivo do presente artigo foi desenvolver uma reflexão teóricometodológica acerca da adoção de metodologias qualitativas em pesquisas voltadas à compreensão geográfica do clima. As discussões estão balizadas pelo exemplo da rotina de trabalho de varredoras(es) de ruas de Presidente Prudente/SP. A atividade em foco é realizada a céu aberto, em uma cidade tipicamente tropical. Sob esta situação, questiona-se quais poderiam ser as relações e percepções dessas(es) trabalhadoras(es) com os elementos atmosféricos? Certamente, suas experiências e percepções em relação ao clima se diferem de outros sujeitos como, por exemplo, aqueles que atuam em locais fechados. A discussão busca centralizar os sujeitos nas pesquisas em Geografia do Clima e apresentar as potencialidades das metodologias em pesquisa qualitativa.

Palavras-chave: Metodologia Qualitativa. Geografia do Clima. Varredoras(es) de Rua. Presidente Prudente/SP.

\section{BEYOND THE INSTRUMENTAL RECORDS: QUALITATIVE METHODOLOGY FOR CONSTRUCTION OF RESEARCH IN GEOGRAPHY OF CLIMATE}

Abstract: This article is aimed to develop a theoretical - methodological reflection on the incorporation of qualitative methodology in research about understanding the climate. The discussions are marked by the example of the routine work of street sweepers at Presidente Prudente / SP. The focus is on open air activities, in a typically tropical city. What could be the relationships between these workers and the atmospheric elements? Of course, their experiences with the climate differ from other subjects, for instance people working indoors. The discussion aims to centralize the subjects in the research on Geography of Climate and present the potential of methodologies in qualitative research.

Keywords: Qualitative Methodology. Geography of Climate. Street Sweepers. Presidente Prudente/SP.

\section{ADEMÁS DEL REGISTROS INSTRUMENTALES: LA METODOLOGÍA CUALITATIVA EN LA CONSTRUCCIÓN DE INVESTIGACIONES DE LA GEOGRAFÍA DEL CLIMA}

Resumen: El presente artículo tiene el objetivo de desarrollar una reflexión teóricometodológica acerca de la incorporación de metodología cualitativa en investigaciones dirigidas a la comprensión del clima. Las discusiones están balizadas por el ejemplo de la rutina de trabajo de barredoras (es) de calles de Presidente Prudente / SP. La actividad en foco se realiza a cielo abierto, en una ciudad típicamente tropical. ¿Cuáles podrían ser las relaciones de las trabajadoras

\footnotetext{
${ }^{1}$ Universidade Estadual Paulista UNESP, Departamento de Geografia, Presidente Prudente/SP, Brasil, lidianapinhomendes|@gmail.com, https://orcid.org/0000-0001-6752-2346

2 Universidade Estadual Paulista UNESP, Departamento de Geografia, Presidente Prudente/SP, Brasil, tadeu@fct.unesp.br, https://orcid.org/0000-0003-3839-0932
} 
con los elementos atmosféricos? Ciertamente, sus experiencias con el clima se diferencian de otros sujetos, por ejemplo, personas que actúan en lugares cerrados. La discusión busca centralizar los sujetos en las investigaciones en Geografía del Clima y presentar las potencialidades de las metodologías en investigación cualitativa.

Palabras clave: Metodología Cualitativa. Geografía del Clima. Barrenderas(os) de la Calle. Presidente Prudente/SP.

\section{Introdução ${ }^{3}$}

É possível centralizar as experiências dos diferentes sujeitos sociais que vivem e experimentam o espaço geográfico em pesquisas voltadas para a compreensão da dinâmica ambiental? É plausível que aqueles(as) que experimentam o espaço possam defini-lo, ou até mesmo suas memórias possam representar conhecimentos acerca dos aspectos físico-naturais do ambiente? Os sujeitos poderiam oferecer informações tão válidas, quanto aquelas obtidas por meio de os instrumentos clássicos de medida, curvas de tendências, análises de solo e produtos cartográficos?

Os estudos geográficos do clima parecem convergir para definições de sensação térmica que admitem tanto variáveis mensuráveis por instrumentos técnicos, quanto parâmetros fisiológicos, bem como a combinação destes, tal como apontam Monteiro (1993), Viana (2013), Sartori (2000). Esta é uma ideia recorrente, porém são poucas as pesquisas que se preocupam em conhecer os sujeitos, suas experiências e subjetividades, nesta área do saber. De acordo com Sartori (2014):

O clima representa papel estratégico na percepção do homem em relação ao meio ambiente. A percepção do clima pelo homem influencia em seu ajustamento ao meio atmosférico. Como os indivíduos percebem o clima é a parte principal no campo da percepção ambiental, pois ele está na interface entre as pessoas e o ambiente (SARTORI, 2014, p. 15).

Monteiro (1993) menciona a dificuldade em se apreender as dinâmicas atmosféricas, a partir de como elas são percebidas pela população. Neste sentido, observações devem ser feitas em relação as nossas memórias. De acordo com a autora:

A reação das pessoas à variabilidade climática depende muito mais da magnitude dos efeitos imediatos ou da semelhança com experiências vividas e memorizadas anteriormente, do que

\footnotetext{
${ }^{3} \mathrm{O}$ artigo foi elaborado pelas reflexões desenvolvidas na disciplina: Pesquisa Qualitativa, ministrada pelo Prof. Dr. Nécio Turra Neto para o Programa de Pós-Graduação em Geografia, FCT UNESP, no segundo semestre de 2017. E também pelas reflexões desenvolvidas no projeto de mestrado: "O trabalho subalterno sob condições adversas do clima: análise da rotina laboral das(os) varredoras(es) de ruas de Presidente Prudente/SP" fomentado pela Fundação de Amparo à Pesquisa do Estado de São Paulo (FAPESP processo n. 2017/02399-9).
} 
propriamente da natureza e relevância dos processos envolvidos. [...]. As variações que se diluem por períodos de tempo muito longos não são perceptíveis, nem o são os fenómenos indefinidos no tempo ou cujos efeitos só são apreciados de forma indirecta, ou ainda, os que não sejam diretamente responsáveis por danos graves e, sobretudo, aqueles que não tenham ocorrido anteriormente (MONTEIRO, 1993, p. 22 - 23).

Assim como bem pontuado por Monteiro (1993), existe discrepância entre o "clima real" e o "clima percebido", tal como definiu Sartori (2014). Para esta pesquisadora o primeiro corresponde à análise climatológica objetiva, baseada em séries sistemáticas e homogêneas de dados corretamente registrados. Enquanto que clima percebido está intrinsicamente relacionado as experiências e vivências pessoais. Para a autora, apesar da complexidade da percepção do tempo e do clima e de suas desconexões em relação à realidade correspondente, o percebido tem grande valor e não pode ser dispensado.

Se por um lado a memória não é aconselhável para um traço linear temporal sobre a dinâmica climática (isto se deve em partes pela escala temporal climática, muito se diferenciar da escala temporal humana), por outro ela é reveladora de verdades outras. Como por exemplo, a influência midiática na difusão do catastrofismo climático propagado e reproduzido nos discursos.

Trata-se apenas de um exemplo que não necessariamente resulta nestas conclusões, mas que viabiliza o acesso a quase infinitas possibilidades do subjetivo, que percebe, experimenta, vive e interpreta o mundo ao seu redor. Portanto, o clima percebido muito interessa aos estudos geográficos do clima e da climatologia geográfica.

Nesta perspectiva, construir abordagens e metodologias que possam estar adequadas para resolução de problemas associados aos impactos e manifestações do clima percebido, para além dos parâmetros tecnológicos e dos vieses quantitativos, torna-se particularmente importantes. Por sua vez, são as metodologias qualitativas atualmente as estratégias mais interessantes que podem evidenciar essa realidade e potencializar o rigor metodológico e a natureza geográfica do clima.

Olharemos para o cotidiano laboral de varredoras(es) de ruas de Presidente Prudente/SP, tendo em vista as potencialidades da pesquisa qualitativa. Para além do registro do termômetro, quais as minúcias do cotidiano destas(es) trabalhadoras(es) em termos sensação térmica e percepção ambiental? Será que 
quando "adentramos a cidade para tomar-lhe a temperatura" não nos esquecemos de olhar para os(as) diferentes habitantes deste espaço? Para suas singulares experiências? O que é perdido ao não considerar o clima percebido pelos diferentes sujeitos?

O objetivo central deste artigo é estabelecer uma reflexão capaz de oferecer subsídios para uma construção metodológica adequada ao tema proposto. Sem a pretensão de esgotar nossas discussões, mesmo porque só se conhece a metodologia e como ela funciona na prática (RIBEIRO, 1998).

É importante salientar que não temos a pretensão de escrever um tratado metodológico sobre a adoção de metodologias qualitativas em estudos geográficos do clima. Este ensaio busca elucidar as potencialidades na convergência entre estas duas áreas do saber: a metodologia qualitativa ligada às vertentes humanistas e a Geografia do Clima proposta por Sant'Anna Neto (2004), partindo do exemplo empírico de sujeitos que atuam a céu aberto.

Nosso artigo está estruturado em três partes. A primeira apresenta uma discussão acerca da possível centralidade dos sujeitos na Geografia do Clima. A segunda seção volta-se para a compreensão da natureza da pesquisa qualitativa e das potencialidades da adoção destas nos estudos geográficos do clima. A última parte apresenta resultados de nossas mais recentes e (ainda não concluídas) investigações acerca do trabalho em varrição em Presidente Prudente/SP e o clima experimentado pelas margaridas (nome popularmente atribuído às varredoras de rua).

\section{Os sujeitos na Geografia do Clima: possíveis diálogos}

Sant'Anna Neto (2004), ao discutir a Climatologia Geográfica e propor o paradigma da Geografia do Clima, compreende a necessidade de ir além dos processos dinâmicos e das estruturas temporais e espaciais do clima, afirmando a necessidade do/a geógrafo/a em situar este processo na dimensão socioeconômica e socioambiental:

Isto significa, necessariamente compreender que a repercussão dos fenômenos atmosféricos na superfície terrestre se dá num território, em grande parte, transformado e produzido pela sociedade de maneira desigual e apropriado segundo os interesses dos agentes sociais (SANT'ANNA NETO, 2004, p. 97). 
O autor tece críticas ao que ele chama de estagnação de práticas e métodos em pesquisas voltadas à compreensão conjuntiva da importância e do papel da atmosfera no entendimento das relações entre a sociedade e a natureza (SANT'ANNA NETO, 2004).

Pondera que é preciso superar o tripé: ritmo climático - ação antrópica impacto ambiental, por esta visão ser extremamente naturalista ao que diz respeito à relação sociedade - natureza, que consequentemente minimiza os aspectos de ordem social, econômica e ideológica nas análises do processo de intervenção e apropriação dos recursos naturais. Assim, é preciso considerar que os diversos grupos sociais não experimentam e nem se relacionam com o tempo e o clima urbano da mesma forma (SANTA'ANNA NETO, 2004).

Ao encontro com as questões propostas pelo autor, concordamos com a necessidade da busca de métodos que explicitam de forma satisfatória as relações entre clima e produção do espaço. Sobretudo na construção de uma abordagem comprometida em evidenciar os processos que tornam o clima como mais um agente de exclusão e segregação social (SANT'ANNA NETO, 2004, p.68).

Nascimento Junior (2018) nos lembra que a Geografia do Clima não busca eliminar as perspectivas clássicas da Climatologia Geográfica. Uma vez que, estas não se configuram em classificações de diferentes abordagens,

[...] na climatologia geográfica a cidade é o foco do clima urbano, na geografia do clima também. [...]. O exercício, no entanto, se diferencia e se dá pela transformação epistemológica do conceito de clima (fenômeno natural socialmente apropriado) e da cidade (forma-conteúdo do urbano), o que requer trazer para a análise do clima urbano, não somente, o sítio e malha urbanos, mas também os processos de urbanização, os modos de vida urbanas, o cotidiano social em sua ordem espacial (Destaques nossos, NASCIMENTO JUNIOR, 2018, p. 11).

O autor supracitado compreende que para este desafio seja necessário a combinação de abordagens dos estudos geográficos do clima. Este nos oferece uma estratégia na qual relaciona os mecanismos que caracterizam eventos extremos no Subsistema Hidrometeórico e inclui na análise o conceito de risco climático (perigosuscetibilidade-vulnerabilidade).

Destacamos o trabalho de Nascimento Junior (2018), devido a preocupação em não restringir suas análises a um viés estritamente descritivo e destacar os problemas da produção do espaço, a saber: as desigualdades, segregação, 
pobreza, etc. Também nos preocupamos em ultrapassar os limites de uma análise estritamente descritiva. No entanto, apresentamos outra estratégia. Nossos esforços convergem para a valorização da apreensão dos fenômenos atmosféricos a partir da experiência de diferentes sujeitos.

Para Sartori (2014), no Brasil são quase inexistentes estudos de percepção climática. Para a autora, ligar as reações humanas a padrões específicos de tempo requer que os sintomas sejam melhor e mais objetivamente verificáveis, que 0 tempo seja mais bem classificado em fases definidas e que se defina correlação estatística entre a fase do tempo e o sintoma humano (SARTORI, 2014, p. 20).

Por isso, talvez, a corrente de pensamento mais comprometida com essa questão seja a humanista. Apesar de presente no conjunto das obras de climatologia brasileira, as investidas humanistas parecem fluir para pontos em comum:

No estudo do Sistema Clima Urbano, Canal I - Conforto Térmico, foram identificadas pesquisas que correlacionam os resultados de comportamento climático obtidos através dos procedimentos metodológicos hipotéticos-dedutivos com alguns lineamentos da corrente de pensamento fenomenológica-hermenêutica, numa tentativa de recuperar o humanismo na elaboração desse sistema. A percepção do clima urbano é pesquisada com a aplicação de questionários e entrevistas que visam apreender o significado das experiências vividas pela população no cotidiano dos lugares e a identificação de mapas mentais elaborados pelas pessoas que convivem com o clima das cidades. Ao final dessas investigações é verificado que a percepção da população é diferente dos resultados apresentados pelo mapeamento dos dados climáticos coletados (ELY, 2006, p. 112).

É de se esperar que as informações derivadas da pesquisa qualitativa sejam discrepantes dos dados meteorológicos. Não é demérito. São informações de natureza distinta, produzidas de formas singulares e suas interpretações não devem ser submetidas a um modo único de interpretação. Por esse motivo pode existir certa insatisfação quando as informações verbais não coincidem com as informações meteorológicas.

De outro modo, Sorre (2006) menciona que:

[...] a idéia de clima é inseparável de suas conexões. Se, na sua origem ela é impregnada de biologia porque só os sentidos percebem as variações atmosféricas, em um estágio bem mais avançado do desenvolvimento científico quando se adquire uma idéia mais correta das relações entre o meio e a vida, ela reencontra, se assim se pode dizer, sua cor biológica [...] (SORRE, 2006, p 89-94). 
Dentro do contexto proposto, a escala do clima emerge como uma questão fundamental para aferição do clima percebido. O sentido é de que ela pode ser interpretada como um contrassenso na discussão, uma vez que, na climatologia ela - a escala - é considerada como uma proporção matemática. De acordo com Ely (2006):

As propostas de escalas climáticas apresentadas permitem a verificação de que os estudos analisados concebem a escala enquanto uma proporção matemática em que são considerados os elementos e fatores do clima em suas expressões extensivas [...] associadas ao seu ritmo [...]. É a escala adotada que define, a priori, qual será a metodologia empregada na análise do clima (ELY, 2006, p. 129).

Concordamos com Santos e Silva (2014) que a escolha da escala define o que é ocultado e revelado: "Assim é responsabilidade do pesquisador justificar suas escolhas teórico-metodológicas, explicitando as contribuições e as limitações de cada escala para o objeto específico" (SANTOS; SILVA, 2014, p. 25).

Sant'Anna Neto (2013) contribui com esta discussão na medida em que entende que as escalas do clima se configuram como um instrumento de análise fundamental para a compreensão das relações temporais e espaciais entre o clima e a superfície terrestre, estas interações pressupõem a concepção das escalas enquanto processos. De acordo com o autor:

De qualquer forma, em função da escala de análise dos processos interativos entre a atmosfera e a superfície terrestre [incluindo-se aqui os espaços produzidos pela sociedade] é que são determinadas as estratégias de abordagem, os métodos a serem empregados e as técnicas de análise apropriadas (SANT'ANNA NETO, 2013, p. 91).

Outra possiblidade de questionamento da escala como proporção matemática é demonstrada por Smith (2000) quando menciona que a divisão do mundo em localidades, regiões, nações e etc, é considerada essencialmente natural e questiona o esvaziamento do debate político sobre a escala:

Primeiramente, a construção da escala geográfica é um meio primário mediante o qual "ocorre" a diferenciação espacial. Em segundo lugar, uma compreensão da escala geográfica poderia nos proporcionar uma linguagem mais plausível da diferença espacial. Em terceiro lugar, a construção da escala é um processo social, isto é, a escala é produzida na sociedade e mediante a atividade da sociedade que, por sua vez, produz e é produzida por estruturas geográficas de interação social. Por fim, a produção da escala geográfica é um lugar de luta política potencialmente intensa (SMITH, 2000, p. 139). 
De acordo com o autor supracitado o local físico primário da identidade pessoal, a escala do corpo, é socialmente construído. O lugar do corpo marca a fronteira entre o eu e o outro em um sentido tanto físico quanto social, e envolve a construção de um "espaço pessoal", além de um espaço fisiológico literalmente definido. Como lugar do prazer e da dor, também tem vontades, desejos e medos, e é o órgão biológico em torno do qual as definições de doença e saúde são construídas. O cuidado com o corpo, o acesso físico ao corpo e pelo corpo e o controle sobre corpo são as avenidas centrais da disputa nessa escala (SMITH, 2000).

Diante destas contribuições, o que se pode inferir é que para uma proposta humanista de análise geográfica do clima a escala climática não pode ser compreendida como uma proporção matemática. Exemplificaremos. Smith (2000) nos instiga com a adoção de uma escala aparentemente singela, como a de um carrinho de supermercado utilizada por moradores de ruas norte-americanos. 0 autor ao centrar suas análises neste objeto, estabeleceu conexões com processos manifestos em escalas mais abrangentes e revelou dinâmicas, até então invisibilizadas.

Assim como Smith (2000), partimos de um contexto social muito particular, mas igualmente conectado com outras realidades, com fenômenos e processos evidenciados em escalas superiores e que também resguardam dinâmicas invisiblizadas.

No nosso exemplo, as(os) varredoras(es) dentre tantos(as) outros(as), não podem escolher como se expõem aos diferentes tipos de tempo. Atuam em ruas e avenidas, em espaços públicos abertos, alvos de olhares, porém pouco notadas(os), submetidas(os) ao encontro e ao imprevisível. O clima neste caso não é uma variável passível de controle, pelo contrário é uma variável que exerce papel determinante na saúde e bem-estar destes indivíduos.

É neste contexto que pensamos em vivência desigual do clima, e que necessariamente requer outra dimensão escalar para além da proporção matemática. Sugerimos pensar o clima e suas escalas a partir das pessoas, da experiência, do cotidiano, do subjetivo, da percepção, da opinião e da sensação térmica pessoal. Esta é nossa escala.

Sabe-se que os elementos climáticos que são passíveis de aferições, são dados abstratos obtidos inclusive por parâmetros estatísticos e matemáticos. No 
entanto, defendemos que os diferentes sujeitos possam exprimir suas interpretações destes dados a partir do subjetivo e da experiência em valores concretos.

Para Tuan (2013) experiência é um termo que abrange as diferentes formas de um sujeito conhecer e construir a realidade. Sendo que, esta relação se dá desde sentidos mais passivos como olfato, paladar e tato, até a percepção visual ativa e a maneira indireta de simbolização.

Experiência é a capacidade de aprender a partir da própria vivência. Está voltada para o mundo exterior, sugere o que uma pessoa tem suportado ou sofrido. Ela é constituída de sentimento/emoção e pensamento, ambas são, igualmente, maneiras de conhecer (TUAN, 2013).

Sorre (2006) afirma que os estudos do clima são inseparáveis das preocupações meteorológicas e relembra que os primeiros "registradores" não foram instrumentos de medida, mas sim elementos naturais, em especial a sensibilidade humana: "Não se conhecia o calor e o frio a não ser por seus efeitos sobre o organismo humano" (SORRE, 2006, p. 89 -94).

É este mesmo autor que menciona a existência de diferentes classificações de climas inspiradas em diferentes pontos de vista, para exemplificar este caráter subjetivo atrelado aos estudos do clima.

A relevância de incluir os sujeitos em pesquisas geográficas do clima se deve ao fato de que "[...] a experiência perceptiva é original e irreversível por representar a vida particular de cada indivíduo que Ihe dá o seu real significado" (SARTORI, 2014, p.47). Neste sentido, poderíamos considerar diferentes tipos de definições de climas a partir dos conhecimentos ou experiências dos sujeitos.

A título de exemplo e inspirados em Tuan (2013), Sorre (2006), Sartori (2014) e Sant'Anna Neto (2004) poderíamos mencionar: o clima dos(as) diferentes trabalhadores(as) [a experiência climática de uma(um) varredora(r) muito se diferencia de um(a) professor(a), por exemplo], de diferentes gerações (crianças e idosos são mais vulneráveis em situações de baixa umidade e períodos mais frios), de gênero (do significado das altas temperaturas para uma mulher em período de menopausa), de classe (a tendência na relação dos impactos do clima e da vulnerabilidade socioambiental e socioeconômica), dentre outras possibilidades e intersecções. Cabe destacar que estas não são e não estão fixas, mas sim abertas e mutáveis com o tempo histórico e do cotidiano.

A partir desta exemplificação, é possível pensar, por exemplo, o significado da estação verão com suas respectivas características em ambiente tropical, 
geralmente com altas temperaturas e alto índice pluviométrico. Quais as diferenças de significados desta estação para uma família em férias? E para uma(um) varredora(or) que atua a céu aberto? Para o primeiro, o verão poderia significar fruição, já no segundo caso é um fator de opressão.

Nesta seção objetivamos elaborar uma reflexão acerca da possível centralidade dos sujeitos em climatologia e as questões que, a nosso ver, envolvem esse desafio: os avanços desenvolvidos no âmbito do paradigma da geografia do clima, as experiências humanistas na climatologia, a questão da escala, as relações espaço-tempo e a experiência como um ponto central em nossas reflexões.

A próxima seção estará voltada a adoção da pesquisa qualitativa como uma intermediária possível na construção de uma climatologia centrada na valorização da experiência dos diferentes sujeitos sociais.

\section{As potencialidades da pesquisa qualitativa}

Assim como nos alerta Mendonça (2001), ainda que a problemática ambiental parta de uma ótica social, a natureza não deve ser entendida a partir de métodos específicos dos estudos da sociedade, assim como a sociedade não o deve ser, a partir de métodos das ciências naturais. $\mathrm{O}$ autor menciona que:

[...] a questão ambiental, para ser levado a cabo com profundidade e na dimensão da interação sociedade-natureza, rompe assim com um dos clássicos postulados da ciência moderna, qual seja, aquele que estabelece a escolha de apenas um método para a elaboração do conhecimento científico (MENDONÇA, 2001, p. 125).

O próprio termo socioambiental indica a insuficiência de pensar em meio ambiente apenas considerando a natureza. "Socio" aparece atrelado ao termo "ambiental" para enfatizar o necessário envolvimento da sociedade/sujeito parte fundamental dos processos relativos à problemática ambiental, assim como explica Mendonça (2001).

Para Moraes (1997), uma abordagem crítica da questão ambiental deve considerá-la como uma manifestação de processos sociais, pelas quais uma dada sociedade organiza o acesso e uso dos recursos naturais disponíveis, organizações que se articulam na própria estruturação social, construindo parte do processo global de sua reprodução. 
Com isto, queremos afirmar a natureza como uma ideia, uma abstração, e sua apreensão demanda métodos investigativos que contemplem diferentes racionalidades.

Becker (1999) nos convida a investir em um modelo artesanal de pesquisa. Nesta proposta está embutida uma crítica às metodologias convencionais, sobretudo aquelas que apresentam modelos prontos, aplicáveis invariavelmente a qualquer realidade que se pretenda estudar.

Ao propor isto, Becker (1999) abre um amplo campo de possibilidades em fazer pesquisa. $O$ autor valoriza a experimentação, a autonomia do(a) pesquisador(a), a inovação de metodologias e teorias adequadas à problemática investigada e até mesmo a divulgação dos erros das pesquisas.

Neste mesmo sentido, Ribeiro (1998) incita o "espírito de risco" nos(as) pesquisadores(as). Rejeita, assim como Becker (1999), a aplicação mecânica de bibliografias e metodologias. Afirma que "[...] o método é algo que nós vamos constituindo à medida que pesquisamos [...]. Só ao término do trabalho é que sabemos como ele funcionou" (RIBEIRO, 1998, p. 191). Portanto, não se trata de adaptar o problema investigado a teorias e métodos pré-estabelecidos.

Não significa que $o(a)$ pesquisador(a) deve ignorar as produções científicas anteriores. Significa tomar conhecimento destas de forma aprofundada e igualmente conhecer o objeto de estudo:

[...] é estar atento aos pontos em que a bibliografia e nosso corpus estão de acordo, mas também àqueles em que irrompe a divergência. Aqui está o eixo do que vim afirmando: nunca aplicar mecanicamente uma chave a um problema (RIBEIRO, 1998, p. 194).

Neste sentido, conhecer a rotina de trabalho em varrição, bem como as relações clima, trabalho e saúde, não bastam os registros meteorológicos. O que se propõe é valorizar a interpretação, a memória, convidar os atores investigados para construção da pesquisa. É incitar o pesquisador e leitor a olhar para uma realidade diferente do seu lugar de mundo, inclusive quando se fala sobre a dinâmica atmosférica.

Apesar de interessante, a discussão sobre uma metodologia específica em pesquisa qualitativa (entrevistas, pesquisa participativa, história oral, etc) pode reduzir demasiadamente sua finalidade. Por isso o destaque das vantagens e potencialidades presentes em boa parte de pesquisas qualitativas pode ser o melhor caminho para de fato estabelecer que a discussão é sobre a natureza da informação 
resultante da pesquisa e matéria prima para elaboração do conhecimento (TURRA NETO, 2012).

O que se busca, na pesquisa qualitativa, é a valorização de fontes de natureza discursiva, aquelas que o autor define como:

[...] um relato, uma história de vida, uma descrição de um fenômeno, cujo tratamento exige técnicas outras e as formas de representação são, sobretudo, extratos dos próprios discursos, tomados como representativos daquilo que o investigador quer expressar (TURRA NETO, 2012, p.2).

Turra Neto (2012) com base em Bogdan e Biklen (1994) menciona que as informações qualitativas são ricas em pormenores descritivos e oferecem complexo tratamento, difícil sistematização e não são informações próprias para um tratamento estatístico, por exemplo. Sendo a imaginação, a habilidade e destreza interpretativa do pesquisador(a) o atributo mais requisitado.

O autor estabelece paralelos ao que ele chama de "metodologia qualitativa como complemento" e "metodologia qualitativa como centro da pesquisa". O primeiro caso, como o próprio nome diz, refere-se às pesquisas que adotam metodologias qualitativas como um complemento a outras metodologias - quantitativas por exemplo. Na segunda:

[...] o eixo central da pesquisa são as informações de natureza qualitativa. No caso da geografia, tratam-se de pesquisas que tem seu foco no sujeito, mais do que nos espaços. São pesquisas que se perguntam pelas práticas espaciais, pelas formas de apropriação do espaço, pela territorialização e geograficidade de pessoas e grupos sociais. Isso não significa que pesquisas que focam nos sujeitos não possam optar por metodologias de cunho quantitativo, mas sim que pesquisas que optam por metodologias de cunho qualitativo como seu eixo estruturador, são pesquisas que necessariamente, tem foco nos sujeitos sociais (TURRA NETO, 2012, p. 3).

Como nos alerta Turra Neto (2012, p. 5) é preciso reconhecer que o discurso construído:

[...] sobre a realidade são os discursos possíveis e seus limites são dados pelas formas de conduzir a pesquisa. Neste sentido o autor traz a ideia de ciência modesta para designar pesquisas de cunho qualitativo, uma vez que esta aceita suas limitações e abre mão da autoridade científica, convidando o(a) leitor(a) para o diálogo.

Quando se adota esta abordagem na pesquisa é preciso considerar que toda narrativa apresenta uma versão, um ponto de vista, sobre algo. Amado (1995) 
menciona que entrevistas podem e devem ser utilizadas como informação e como qualquer outro documento, devem ser submetidas a contraprovas e análises. Esta metodologia fornece pistas e informações que dificilmente poderiam ser obtidas por outros meios.

Meihy (1996) destaca a relevância da história oral como um recurso para grupos minorados, silenciados e excluídos dos mecanismos de registros da história. Poderíamos estender essa assertiva para outras metodologias em pesquisa qualitativa: a capacidade de evidenciar as histórias, experiências e interpretações daqueles(as) que são pouco ouvidos(as).

A assertiva ganha expressividade quando estão em foco sujeitos marcados pela invisibilidade e subalternidade, assim como as(os) varredoras(es). Aquelas(es) que executam atividades de pouco reconhecimento social, atividades simples, de baixo prestígio social e que não têm suas histórias e experiências expressas em livros, assim como as(os) varredoras(es).

Não pretendemos esgotar nossas discussões acerca da adoção de metodologias qualitativas em pesquisas da Geografia do Clima ou pesquisas de cunho socioambiental num geral. Procuramos desenvolver uma reflexão capaz de abrir possibilidades nessa área do saber. Bem como, apresentar um ponto de intersecção que parece estar presente em boa parte destas metodologias: a capacidade de evidenciar a experiência de sujeitos que a história convencional não retrata.

Além disto, todos(as) nós temos uma ideia pré-estabelecida sobre o clima que experimentamos. O que nossas opiniões podem comunicar? E quanto as(os) varredoras(es), o que seus diferentes discursos podem comunicar em relação ao clima que experimentam?

Eis o nosso desafio: tecer um caminho metodológico capaz de evidenciar as experiências destas(es) trabalhadoras(es) em seus contextos climáticos. A partir de um processo de pesquisa autoconsciente que reconhece que pesquisas de cunho qualitativo integram o(a) pesquisado(a), o(a) pesquisador e o(a) leitor(a) em uma construção horizontal, aberta, interpretativa e mutável. 


\section{Algumas considerações sobre as(os) varredoras(es) de rua de Presidente Prudente/SP}

A atividade laboral em foco é marcada por uma exposição prolongada aos elementos atmosféricos. As(os) varredoras(es) experimentam cotidianamente o clima, no caso, tropical sub úmido, nos horários de maior irradiação solar (12:00) e aquecimento diurno (15:00 - 16:00), acrescido das características citadinas, o clima urbano de Presidente Prudente/SP.

Em Presidente Prudente/SP são aproximadamente 60 dias por ano com temperaturas máximas superiores a $33^{\circ} \mathrm{C}$ e 138 dias com temperaturas acima dos $31^{\circ} \mathrm{C}$ (FANTE, 2014). A autora destaca que de acordo com a OMS (Organização Mundial da Saúde), máximas superiores a $30^{\circ} \mathrm{C}$ já se situam em estado de atenção para a saúde pública.

A cidade já esteve no cerne de vários estudos acerca de seu clima e do clima urbano, com destaque os trabalhos de Amorim (2000; 2017). Essas teses são indispensáveis para a discussão proposta. No entanto, procuramos partir de outro referencial, que não os dados passíveis de aferições. Centramos nossas atenções em sujeitos que possuem suas rotinas laborais em ambientes externos, a céu aberto, no caso varredoras(es) de rua.

O trabalho é recorrentemente compreendido como uma mediação orgânica entre o meio ambiente e o trabalhador, um elo que os une e os transforma dialeticamente. Por exemplo, Tuan (2012) menciona que quando os trabalhadores franceses sentem dor e cansaço eles dizem que "seus ofícios formam parte deles". Não se trata apenas de uma metáfora, "[...]os músculos e as cicatrizes testemunham a intimidade física do contato" (TUAN, 2012, p. 140). O que os músculos e cicatrizes podem nos ensinar sobre o ambiente que os trabalhadores conhecem tão intimamente?

Em etapas de investigação anteriores (MENDES, 2016), entrevistas semiestruturadas foram realizadas com treze varredoras(es) de ruas de Presidente Prudente/SP. O contato primeiro com as(os) varredoras(es) nos aproximou do cotidiano de trabalho destas(es). Pode-se dizer que foi uma etapa exploratória. Realizamos também entrevistas semiestruturadas com um representante sindical, um técnico em segurança do trabalho e um membro da empresa responsável pela limpeza pública de Presidente Prudente/SP. 
Algumas informações relevantes derivadas desses momentos anteriores devem ser destacadas: a função é realizada majoritariamente por mulheres, grande parte destas possuem idade avançada, é uma atividade de pouca rotatividade, a maior parte da função é realizada em período diurno/vespertino e no escopo de atuação está incluída, além da varrição, a capina.

O trabalho em foco reúne um conjunto de situações cotidianas desfavoráveis, como: trabalhar a céu aberto, andar durante um turno de oito horas, executar movimentos repetitivos, muitas vezes encurvadas(os), estar em contato direto com o lixo urbano, permanecer em vias de grande movimentação de veículos, sem local próprio de descanso, almoço e até mesmo de usar o banheiro. Somado a isso a atividade é pouco valorizada, de baixo prestígio social e de débil reconhecimento, caracterizando a invisibilidade da função, assim como identificou Costa (2004).

Apesar de a atividade reunir aspectos desfavoráveis para a saúde e bemestar das(os) trabalhadoras(os), a insalubridade da função não é reconhecida e isto se deve em muito pelo desprestígio social da função e pela atividade ser predominantemente feminina. Isto porque, de acordo com Carloto (2003) acredita-se que os trabalhos de limpeza, dentre outros que contemplam a esfera reprodutiva, fazem parte da "natureza" feminina.

O resultado é a construção de um ideário em que os trabalhos desempenhados por mulheres são leves e sem riscos. A figura 1 representa a relação de sintomas e condição de risco declarados pelas(os) varredoras(es) entrevistadas(os ):

Figura 1: Sintomas e condição de risco declarados por treze varredoras(es) de ruas de Presidente Prudente/SP, 2016

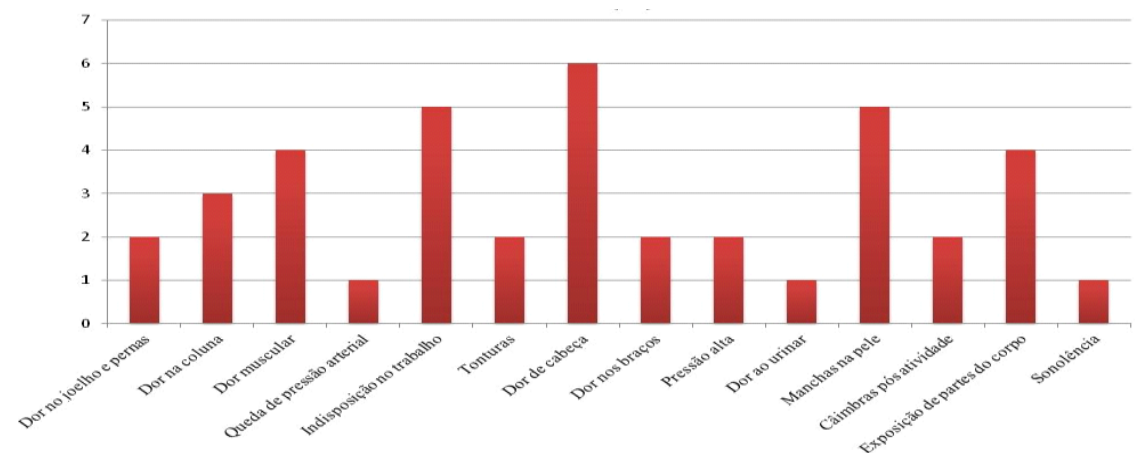

Org: Mendes (2016).

Há o predomínio dos sintomas: dor de cabeça (6), indisposição no trabalho (5), manchas na pele (5), dor muscular (4) e dor na coluna (3). Três destes sintomas 
mais frequentes podem possuir relações com a exposição aos elementos atmosféricos: dor de cabeça, indisposição no trabalho e manchas na pele.

Por outro lado, o representante sindical, o técnico em segurança do trabalho e o membro da diretoria da empresa responsável pela limpeza pública da cidade, demonstraram um não reconhecimento da insalubridade da função.

Não é difícil imaginar que as(os) varredoras(es) atuam em constantes situações de desconforto térmico e que isto afeta negativamente sua saúde e bemestar. Costa (2004) ao atuar como gari faz várias menções ao calor desumano ao qual eram submetidos(as) os(as) trabalhadores responsáveis pela limpeza pública. A partir da pesquisa participativa, o autor adentra nas minúcias do cotidiano em limpeza pública e traz várias contribuições, com destaque à invisibilidade social dos sujeitos que atuam como gari. Destacamos um trecho de um relato oriundo da experiência de Costa (2004) e que possui singular relevância para o presente artigo:

[...] enquanto ficava no ponto de ônibus aguardando o circular com os companheiros, admirava as tonalidades quentes da manhã ensolarada. Repetia ingenuamente "Nossa hoje o tempo tá bom!".

Normalmente um longo silêncio se seguia as minhas palavras. Um ou outro trabalhador olhava para o céu com ar de preocupação. Nada mais. Noutros dias, céu nublado, eu reclamava: "Ih, hoje a coisa tá feia".

Ninguém se manifestava. [...] um dia no mesmo ponto de ônibus, Carlão manifestou-se espontaneamente: "Ih! Hoje o tempo tá ruim Fernando. Olha o céu".

Olhei: O sol brilhava forte [...]. Foi como ter acordado de repente [...]. Os efeitos do sol incomodavam-me demais: sentia o corpo cansar rapidamente, a pele arder, a cabeça parecia muito mais pesada, os olhos ficavam preguiçosos e incomodados com a forte luz que vinha do céu [...], a água colocada na garrafa térmica terminava na primeira meia hora de serviço (e nem sempre estivemos próximos às torneiras), a poeira subia rapidamente ao nariz e aos olhos, a quantidade de baratas e de outros insetos aumentava demais; se o calor era seco, tornava-se difícil respirar [...]; se o calor era úmido, a sensação térmica aumentava assustadoramente. Trabalhar com forte calor, varrer sob o sol, era um verdadeiro inferno.

Meu ponto de vista, meu lugar no mundo - alguém acostumado aos recintos fechados e confortáveis, ao abrigo do frio e do vento, ou do calor escaldante - não me permitiriam, embora tivesse tantas vezes me exposto aos seus efeitos, perceber o impacto orgânico da natureza sobre os garis (COSTA, 2004, p. 193-194).

A pesquisa participativa inseriu o pesquisador em uma realidade diferente da sua, o que possibilitou rupturas de valores pré-estabelecidos acerca do clima. A partir disso, o autor compreendeu que o clima é uma variável passível de 
interpretação orientada pela experiência. Portanto, nossos julgamentos acerca do clima comunicam um lugar no mundo.

Nas fases mais recentes de nossas investigações, entrevistamos uma varredora de rua de Presidente Prudente/SP, e nos tornamos próximos a esta. Visitamos sua casa e somamos esforços para realizar uma entrevista semelhante a um diálogo.

Os argumentos apaziguadores relacionados ao desconforto térmico foram frequentes na entrevista. Sabemos que a temperatura da cidade é constantemente alta e a cidade é pouco arborizada (MENDES; TOMMASELLI, 2019). Em Mendes e Tommaselli (2018) identificamos que nos meses de verão e primavera, as temperaturas consideradas insalubres, por representarem riscos por sujeição térmica aos trabalhadores, chegam a totalizar seis horas de um turno de trabalho de oito horas. Mesmo assim a entrevistada nega ser um problema. Como pode ser observado nos fragmentos do diálogo abaixo:

- Eu sou varredeira, faço de tudo né? Nóis varre, nóis carpe, nóis pinta, nóis tira terra, nóis faz tudo. É que nem na roça, que nem na roça! [...] Graças a Deus me sinto feliz. Eu tomo sol, já acostumei, não tem diferença. $O$ sol é maravilhoso.

- Porque eu vim da roça né? Não teve problema nenhum. [...] Quantos anos que eu estou no sol? [...] Tem hora que o sol irrita, mas não ligo não sabe? Já acostumei, já vim da roça então quer dizer, mesma coisa de ser uma roça né? Nóis faz de tudo um pouco[...] (Destaques nossos, VARREDEIRA, 2018).

Outro aspecto que nos chamou a atenção é a constante menção de seu passado na "roça". Tuan (2013, p. 227) nos explica as pessoas olham para trás, para o passado, por várias razões, mas uma é comum a todos: a necessidade de adquirir um sentido do eu e da identidade. Eu sou mais do que aquilo definido pelo presente fugaz. Compreendemos que a constante menção a um passado laboral rural é a manifestação do trabalho como um valor de identidade e dignidade.

O fragmento da entrevista abaixo merece especial menção por possivelmente possuir ligação com o comportamento diário atmosférico e a frequência de utilização do banheiro pela entrevistada:

- [...] é difícil eu ir no banheiro. É difícil. O banheiro meu é mais antes do almoço, depois do almoço não precisa não (VARREDEIRA, 2018).

É preciso considerar que em Presidente Prudente a tarde é o período de maior aquecimento diurno e que possivelmente existe uma maior perda hídrica pelo 
suor o que diminui o número de micções da entrevistada. Além disso, Shimo (1995) identificou em sua pesquisa sobre varredoras de ruas de São Paulo que a pouca ingestão hídrica é relatada e que as varredoras justificam tal comportamento devido à dificuldade em pedir para usarem o banheiro a moradores nem sempre solidários. Menciona também a utilização desta conduta como uma alternativa para reduzir o número de micções.

Nossa entrevistada nos conta também de suas dores e repete o padrão de atenuar seus problemas de saúde:

De vez enquanto da dor na coluna só e uma dor nesse braço, mas to com consulta marcada dia 24 no postinho. Porque eu tenho que mostrar uma chapa que eu tirei do pé, porque o meu pé tem a junta inchada e tem esse lombinho aqui. Não sei o que é isso não é um caroço [...] mas não me prejudica em nada [...]. Eu acho que a gente vivi de bota o dia inteiro, também pode ser, mas tem dia que dói hen?

Parece que sai do eixo, ai eu tenho que mancar para voltar ao normal, mas não me prejudica em nada (Destaques nossos, VARREDEIRA, 2018).

Dejours (2014) menciona que para o(a) trabalhador(a), e mais intensamente para o subproletariado, a doença está relacionada à ideologia da vergonha de parar de trabalhar, uma vez que, "doença - avesso - do - trabalho". O autor define aquilo que denomina "ideologia defensiva":

A partir do exemplo do subproletariado poderíamos propor algumas características do que seja uma ideologia defensiva. Em primeiro lugar, a ideologia defensiva funcional tem por objetivo mascarar, conter e ocultar uma ansiedade particularmente grave. [...] o que caracteriza uma ideologia defensiva é o fato de ela ser dirigida não contra uma angústia proveniente de conflitos intra-psíquicos de natureza mental, e sim ser destinada a lutar contra um perigo e um risco reais (DEJOURS, 2014, p. 35-36).

"A ideia de 'não prestar mais' para o trabalho desorienta [...]" (KOWARICK, 1976, p. 170). Pensamos que por isso, nossa entrevistada se recusa a admitir sua dor, seu cansaço e seus limites.

O fato de o trabalhador não recusar a segregação de funções, a baixa remuneração, os serviços degradantes, deve-se, sobretudo à nefasta informação da ideologia; informações que cancelam verdadeiros motivos históricos e forjam motivos apaziguadores pelos quais uma classe inteira de homens está a alimentar servilmente de uma outra (COSTA, 2004, p. 161). Quanto a isso e de acordo com Smith (1988): 
Para a classe trabalhadora, a nível do indivíduo e da classe, seja qual for o modo de produção trava-se uma batalha constante entre a conscientização espontânea da vivencia do trabalho diário e as ideias dominantes disseminadas pela própria classe dominante, as quais por mais bem-sucedidas e por mais enraizadas que pareçam estar na vivencia imediata, sempre são encaradas como ideologia abstrata (SMITH, 1988, p. 82).

Destacamos alguns fragmentos da entrevista e algumas possíveis análises. Três pontos possuem particular relevância e merecem ser assinalados: 1. A constante menção do passado laboral se traduz como um valor e um elemento de identidade para a trabalhadora; 2 . Essa característica se reflete nas constantes falas contraditórias, por exemplo, o incomodo com o sol, mas coberto com falas de amortecimento; 3. O clima afeta negativamente a saúde, o bem-estar e o conforto da entrevistada.

Concordamos que "nem sempre os nativos, para falar, precisam que nos sentemos ao lado deles: mas nós, para ouvi-los, precisamos sempre" (COSTA, 2004, p. 47). Esta, talvez, seja a grande potencialidade da pesquisa qualitativa. Assumimos os riscos e reconhecemos a natureza da pesquisa qualitativa e das informações derivadas desta. Porém, creditamos a ela a competência de representar realidades que só podem ser contadas por aqueles(as) que a experimentam.

Caminhando para o término de nosso artigo, gostaríamos que uma essência não fosse perdida a ideia de que sob o julgo do capital não existem dicotomias, em contrapartida para a ciência sim, e infelizmente: "[...] enquanto nós, como teóricos, podemos ter drásticos problemas conceituais em realizar uma integração do espaço e da sociedade, o capital parece realiza-la na prática diariamente" (SMITH, 1988, p. 19). Nossos esforços estiveram direcionados para a construção de uma análise conjuntiva sociedade e natureza no interim dos estudos geográficos do clima. Isto porque, na realidade prática, na vida destas(es) trabalhadoras(es), estas informações se combinam de forma complexa.

\section{Considerações Finais}

A climatologia é um campo científico, em geral, pautado por métodos quantitativos. O presente artigo buscou desenvolver uma discussão que valoriza as potencialidades da pesquisa qualitativa neste campo do saber científico geográfico. 
As discussões foram desenvolvidas a partir de um cotidiano laboral marcado por uma exposição prolongada aos elementos atmosféricos, varrição pública de Presidente Prudente/SP. Trata-se ainda de uma discussão teórica, mas sabemos que as experiências das(os) varredoras(es) acerca do clima, possuem singularidades que não são registradas com o termômetro.

Nossos argumentos se fundamentaram na aproximação do paradigma da Geografia do Clima com concepções oriundas da Geografia Humanista. Encontramos na junção destas a possibilidade de representar estórias, trajetórias e experiências acerca da vivência desigual do clima. Propomos valorizar a experiência e, com isto, as informações de natureza discursiva acerca das interpretações sobre o clima. Apesar de não ter sido destacado uma metodologia específica, destacamos um aspecto que está presente em mais de uma delas: a capacidade de centralizar o conhecimento/vivência de sujeitos marginalizados na história.

Destacamos o exemplo das margaridas e suas rotinas laborais. Nossas aproximações com uma varredora resultaram em discursos muito marcados pela ideologia defensiva. O que nos levou a concluir que esta tolera o fator de risco, no caso insalubridade térmica, devido ao temor ao desemprego, doenças ou acidentes de trabalho, o que se traduz como uma tragédia para aqueles(as) que dispõe apenas de sua força de trabalho para assegurar sua sobrevivência (KOWARICK, 1976).

Portanto, nossa entrevistada se esforça em ocultar seus sintomas, dores, cansaço, doenças, etc, o que incrementa sua vulnerabilidade, pois torna tolerável o que não deveria ser. No entanto, em breves momentos ela irrompe o silêncio e deixa escapar seu descontentamento com o clima, suas dores e exaustão.

Buscamos construir uma visão sensível para a individualidade, e admitir uma reflexão sobre planejamento voltada para aqueles que mais sofrem com as injustiças ambientais. Para isto defendemos a necessidade de ouvir a "varredeira", o pedreiro, os(as) idosos(as), pessoas com deficiência, ou seja, aqueles que são minorados em direitos e que sofrem com mais intensidade as injustiças ambientais. Nossa redação é um convite para novas combinações teóricas e metodológicas voltada para os sujeitos e para os estudos geográficos do clima. 


\section{REFERÊNCIAS}

AMADO, J. O grande mentiroso: Tradição, veracidade e imaginação em história oral. História, São Paulo, 1995.

AMORIM, M. C. C. T. O clima urbano de Presidente Prudente - SP. 2000. 322f. Tese (Doutorado em Geografia Física) - Faculdade de Filosofia, Letras e Ciências Humanas, Universidade de São Paulo, São Paulo.

Teoria e método para o estudo das ilhas de calor em cidades tropicais

de pequeno e médio porte. 2017, 178f. Tese (Livre Docência em "Climatologia Geográfica)

- Faculdade de Ciências e Tecnologia, Universidade Estadual Paulista, Presidente

Prudente/SP.

BECKER, H. S. Métodos de pesquisa em ciências sociais. Tradução ESTEVÃO, M; AGUIAR, R. 4ํeㄹição. Editora Hucitec, São Paulo, 1999, (p. 9 - 46).

CARLOTO, C. M. Adoecimento no trabalho, as mulheres na categoria de asseio e limpeza.

Serviço Social em Revista, Londrina/PR, 6 (1), 2003, (p.39 - 46). Disponível em:

http://www.uel.br/revistas/ssrevista/c_v6n1_cassia.htm

COSTA, F. B. Homens invisíveis: Relatos de uma humilhação social. Editora Globo. São Paulo/SP. 2004.

DEJOURS, C. A loucura do trabalho. Estudos de psicopatologia do trabalho. Tradução: PARAGUAY, A. J; FERREIRA, L. L. Editora Cortez. São Paulo/SP. 5edição. 2014. ELY, D. F. Teoria e método da climatologia geográfica brasileira: uma abordagem sobre seus discursos e práticas. 2006, $208 \mathrm{f}$. Tese (Doutorado em Geografia) Faculdade de Ciências e Tecnologia, Universidade Estadual Paulista, Presidente Prudente/SP, 2006.

ENTREVISTA VARREDEIRA. [Entrevista concedida a]: Lidiana de Pinho Mendes. Presidente Prudente. Agosto. 2018. 1 arquivo wma (30 minutos). A entrevista na íntegra encontra-se transcrita e de posse da autora do trabalho.

FANTE, K. Variabilidade de temperatura em áreas urbanas não metropolitanas do Estado de São Paulo. 2014. 254f. Dissertação (Mestrado em Geografia) - Faculdade de Ciências e Tecnologia, Universidade Estadual Paulista, Presidente Prudente/SP. KOWARICK; L. A espoliação urbana. $2^{\circ}$ edição, Editora Paz e Terra, Rio de Janeiro/RJ, 1976.

MASSEY, D; KEYNES, M. Filosofia e política da espacialidade: Algumas considerações. Traduzido por Haesbaert, R. Revista Geographia, Revista do Programa de Pós-Graduação em Geografia da UFF, Rio de Janeiro, V. 6, № 12, 2004, (p. 7 - 23). Disponível em: http://www.geographia.uff.br/index.php/geographia/article/view/151/146

MENDES, L. P. Rotina laboral sob condições adversas do clima: $O$ caso das(os) varredoras(es) de ruas de Presidente Prudente/SP. 2016. 76 f. Monografia (Bacharel em Geografia) - Faculdade de Ciências e Tecnologia, Universidade Estadual Paulista, Presidente Prudente/SP.

; TOMMASELLI, J. T. G. Os sujeitos na cena: análise das temperaturas dos alvos urbanos de Presidente Prudente/SP - Interpretações a partir da rotina de trabalho de varredoras(es) de ruas. Revista Formação, V. 26, no47, 2019. (p. 159 - 177). Disponível em: http://revista.fct.unesp.br/index.php/formacao/article/view/5541

O trabalho sob condições adversas do clima: Notas sobre o cotidiano laboral de varredoras(es) de ruas de Presidente Prudente/SP/Brasil. In: XVI Colóquio Ibérico de Geografia. 2018. Lisboa/PT. (Anais). Disponível em: https://drive.google.com/file/d/1Ey4N4vhMiYPA526KcPptaz5PEgB7EnJT/view 
MENDONÇA, F. Geografia socioambiental. Revista Terra Livre. São Paulo. nำ16, (p. 139 151), 2001. Disponível em:

http://www.agb.org.br/publicacoes/index.php/terralivre/article/view/352

MEIHY, J. C. S. B. Manual da história oral. Edições Loyola. São Paulo, 1996, (p. 40 - 147).

MONTEIRO, A, M, R. O clima urbano do Porto - Contribuições para definição das

estratégias de planeamento e ordenamento do território. 1993. 467 f. Tese (Doutorado

em Geografia). Universidade do Porto, Portugal.

MORAES, A. C. R. Meio ambiente e ciências humanas. $2^{\circ}$ Edição. Editora Hucitec. São

Paulo, 1997.

NASCIMENTO JUNIOR, L. Transformações e permanências dos estudos comparados na geografia. Boletim goiano de geografia. V.37, $n^{\circ} 2$, (p. $303-322$ ), 2017, acesso em janeiro de 2019.

O clima urbano como risco climático. Revista GeoUERJ. n³4,

Rio de Janeiro/RJ, 2018.

RIBEIRO, R. J. Não há pior inimigo do conhecimento do que a terra firme. Tempo Social

Revista de Sociologia da USP, São Paulo, V. 10, no2, (p. 189 - 195), 1998. Disponível em: http://www.revistas.usp.br/ts/article/view/12300

SANT'ANNA NETO, J. L. História da climatologia no Brasil. Cadernos Geográficos, UFSC, Florianópolis/SC. V. 7, (p. 1-124), Maio de 2004. Disponível em:

http://cadernosgeograficos.ufsc.br/files/2016/02/completo-7.pdf.

Escalas geográficas do clima. Mudança, variabilidade e ritmo. In:

Margarete Cristiane de Costa Trindade Amorim; João Lima Sant'Anna Neto; Ana Monteiro.

(Org.). Climatologia urbana e regional: questões teóricas e estudos de caso. São

Paulo. Editora Outras Expressões, 2013, (p. 75-92).

SANTOS, E. O; SILVA, F. A. C. Revisitando o conceito de escala na geografia. Boletim de geografia. Maringá/PR. V. 32, n³, 2014, (p. 16-27). Disponível em:

http://www.periodicos.uem.br/ojs/index.php/BolGeogr/article/view/19554.

SARTORI, M. G. B. Clima e percepção geográfica - Fundamentos teóricos a percepção climática e à bioclimatologia humana. Santa Maria/RS. Editora Palloti., 2014.

SHIMO, A. K. L. Criando um sanitário portátil: Uma contribuição da enfermagem para as varredoras de ruas. 1995. 173f. Tese (Doutorado em Enfermagem) - Escola de Enfermagem, Universidade de São Paulo, Ribeirão Preto/SP.

SMITH, N. Desenvolvimento desigual - Natureza capital e a produção do espaço.

Tradução: Navarro, E. A. Rio de Janeiro. Editora Bertrand Brasil S. A. 1988.

Contornos de uma política especializada: veículos dos sem-teto e produção

de escala geográfica. In: ARANTES, Antonio A. (org.). 0 espaço da diferença.

Campinas/SP. Editora Papirus. 2000 (p. 132-175).

SORRE, M. Objeto e Método da climatologia. Tradução CONTI, J. B. Revista do

Departamento de Geografia FFLCH/USP. São Paulo/SP. P. 89-94. 2006.

Disponível em:

http://www.geografia.fflch.usp.br/publicacoes/RDG/RDG 18/RDG18 089 094.pdf.

TUAN, Y. F. Topofilia - Um estudo da percepção, atitudes e valores do meio ambiente.

Tradução: OLIVEIRA, L. Editora de Universidade Estadual de Londrina (UEL), Londrina, PR, 2012.

Espaço e lugar - a perspectiva da experiência. Tradução:

OLIVEIRA, L. Editora de Universidade Estadual de Londrina (UEL), Londrina, PR, 2013.

TURRA NETO, N. Pesquisa Qualitativa em Geografia. In: XVI Encontro Nacional de

Geógrafos. Belo Horizonte/MG. 2012 (Anais), (p.1-10).

VIANA, S. S. M. Conforto térmico nas escolas estaduais de Presidente Prudente/SP.

2013. 218f. Tese (Doutorado em Geografia) - Faculdade de Ciências e Tecnologia,

Universidade Estadual Paulista, Presidente Prudente/SP. 


\section{NOTAS DE AUTOR}

\section{CONTRIBUIÇÃO DE AUTORIA}

Lidiana de Pinho Mendes - Concepção e elaboração do manuscrito, Coleta de dados, Análise de dados, Elaboração do manuscrito, Participação ativa da discussão dos resultados.

Prof. Dr. José Tadeu Garcia Tommaselli - Orientação, Revisão e aprovação da versão final do trabalho.

\section{FINANCIAMENTO}

Pesquisa fomentada pela Fundação de Amparo à Pesquisa do Estado de São Paulo - FAPESP, processo $\mathrm{n}^{\circ}$ : 2017/02399-9.

Inserir a fonte de apoio na forma de bolsa, equipamentos, produtos ou recursos, indicar a instituição que financiou a pesquisa, o número do projeto/processo e anexar a comprovação em documento suplementar. Caso não tenha recebido mencionar: Não se aplica.

\section{CONSENTIMENTO DE USO DE IMAGEM}

Não se aplica.

\section{APROVAÇÃO DE COMITÊ DE ÉTICA EM PESQUISA}

Não se aplica.

\section{CONFLITO DE INTERESSES}

Informar conflitos de interesse: financeiros, pessoais, entre possíveis revisores e editores, possíveis vieses temáticos. Para mais informações: https://www.abecbrasil.org.br/arquivos/whitepaper_CSE.pdf

\section{LICENÇA DE USO}

Este artigo está licenciado sob a Licença Creative Commons CC-BY. Com essa licença você pode compartilhar, adaptar, criar para qualquer fim, desde que atribua a autoria da obra.

\section{HISTÓRICO}

Recebido em: 19-11-2018

Aprovado em: 25-08-2019 